University of the Pacific

Scholarly Commons

All Faculty Articles - School of Engineering and Computer Science

All Faculty Scholarship

$12-1-2019$

\title{
Fluids Demonstrations II: Bubbles in Mondrian Painting, Eruption- Like Flow, Rotational Instability, and Wake Vortices
}

\section{Said Shakerin}

University of the Pacific, sshakerin@pacific.edu

Follow this and additional works at: https://scholarlycommons.pacific.edu/soecs-facarticles

Part of the Mechanical Engineering Commons

\section{Recommended Citation}

Shakerin, S. (2019). Fluids Demonstrations II: Bubbles in Mondrian Painting, Eruption-Like Flow, Rotational Instability, and Wake Vortices. Physics Teacher, 57(9), 600-603. DOI: 10.1119/1.5135786

https://scholarlycommons.pacific.edu/soecs-facarticles/93

This Article is brought to you for free and open access by the All Faculty Scholarship at Scholarly Commons. It has been accepted for inclusion in All Faculty Articles - School of Engineering and Computer Science by an authorized administrator of Scholarly Commons. For more information, please contact mgibney@pacific.edu. 


\section{$\prod_{0}^{-1}$ Mondrian Painting, Eruption-Like Flow, Rotational Instability, and Wake Vortices}

Fluids Demonstrations II: Bubbles in

Cite as: Phys. Teach. 57, 600 (2019); https://doi.org/10.1119/1.5135786

Published Online: 26 November 2019

\section{Said Shakerin}

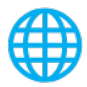

\section{ARTICLES YOU MAY BE INTERESTED IN}

Electric Circuits as Seen by Thermal Imaging Cameras

The Physics Teacher 57, 597 (2019); https://doi.org/10.1119/1.5135785

Electrocardiography with a Smartphone

The Physics Teacher 57, 586 (2019); https://doi.org/10.1119/1.5135782

Polarization Imaging Application with Smartphones

The Physics Teacher 57, 594 (2019); https://doi.org/10.1119/1.5135784

\section{AAPT}

Advance your teaching and career as a member of AAPT 


\section{Fluids Demonstrations II: Bubbles}

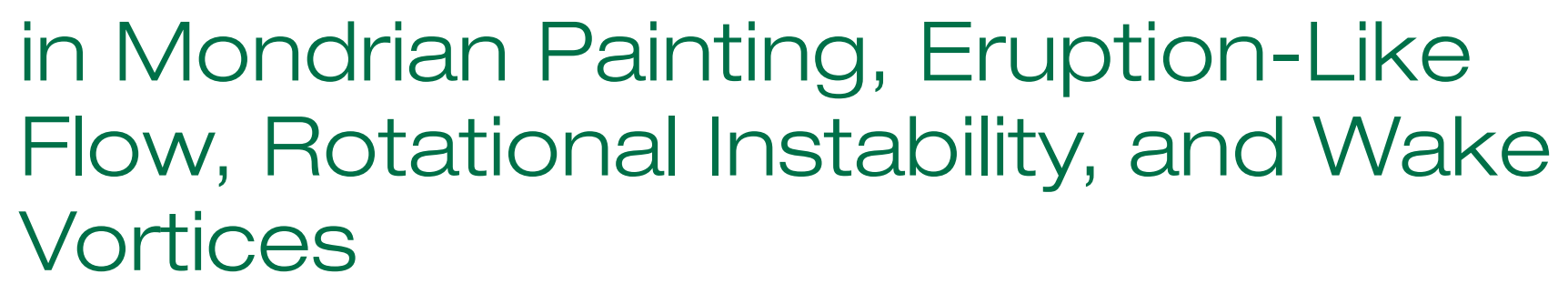

Said Shakerin, University of the Pacific, Stockton, CA

$\mathrm{T}$ The purpose of this paper is to present five new devices that demonstrate a variety of flow phenomena in liquids and granular materials that exhibit fluid-like behavior. These devices complement and add on to a recent collection of demonstrations that was published in this journal. ${ }^{1}$ The devices are self-contained and portable, and can be utilized repeatedly without waiting or cleanup between uses. Furthermore, since the demonstrations result in visually engaging patterns, they are accessible to everyone regardless of age or science background. Descriptions are provided to enable replication by others. Significance of each demonstration is outlined and background information on the relevant physics can be found in the cited references. Pedagogical directions for specific use are left to the discretion of readers (depending on the scope of local interests and constraints). However, they can be used in classroom lecture demonstrations, outreach activities, or other student-based projects.

\section{Description}

All devices are made of acrylic sheet and round stocks with fabrication methods similar to those reported earlier. ${ }^{1,2}$ An itemized list of materials and supplies with a total budget of US $\$ 240$ is provided in Appendix A. ${ }^{3}$ Videos of sample demonstrations are available with the online version of the paper. $^{3}$

\section{Bubbles in Mondrian painting}

A thin enclosure, which contains dyed glycerin and air in three sealed sections, demonstrates air bubble motion in a viscous liquid. The enclosure was primarily designed as a decorative device. However, if the enclosure is turned upside down multiple times, larger bubbles eventually break into smaller bubbles. The reason is that the falling glycerin has a tendency to break through the flattened surface of the rising bubble and divide it into two (smaller) bubbles. Following that, some aspects of bubble dynamics are visualized too. For example, if and when two bubbles that are almost vertically aligned rise near each other, the lower bubble usually catches up because it has lesser drag compared to the leading bubble, and the bubbles merge. The fascinating topic of bubbles is of contemporary interest due to its occurrence in numerous applications in science and technology. 4,5

The enclosure is made entirely of acrylic sheet stock, with frontal dimensions of $25.4 \times 20.3 \mathrm{~cm}(10 \times 8$ in) [see Fig. 1(a)]. The front and back are $3 \mathrm{~mm}$ (1/8 in) thick, clear and white acrylic, respectively. (All dimensions have been converted and rounded to the nearest $\mathrm{mm}$ for brevity. However, in Appendix $\mathrm{A}$, original dimensions are given in inches as all materials were sourced in the United States.) Four 6-mm (1/4-in) wide strips cut from 2-mm (1/16-in) thick acrylic sheet serve as spacers around the enclosure. Several more strips divide up the enclosure into six separate sections (with three of them being empty). This is to resemble one of the paintings of Dutch painter Piet Mondrian (1872-1944). His most famous paintings are abstract compositions of black-bordered rectangles of white, red, blue, and yellow. I added a fluid dynamics twist, namely, air bubbles, to the painting. A small part of an outside strip of each of the sections to be filled with glycerin is cut, but saved, to provide an opening for the later filling of glycerin in that section. All parts, except the small cutouts, are glued together with acrylic cement and left overnight to dry completely. Glycerin is dyed with a few drops of food color and injected into the desired section with a dispensing bottle equipped with a hypodermic needle (with blunt tip). The saved cutout piece for that section is then placed in the opening and glued. This step is repeated for other sections to be filled with glycerin, and in our case, three sections are filled with glycerin (while the other three sections are left empty). Syrup-like acrylic glue is then applied around all edges to further reinforce and seal all joints.

To fabricate this enclosure, or any other enclosure with liquid content, special care is required to ensure the strips are completely glued to both front and back surfaces (i.e., no leaks). Practice on scraps before final fabrication. Further

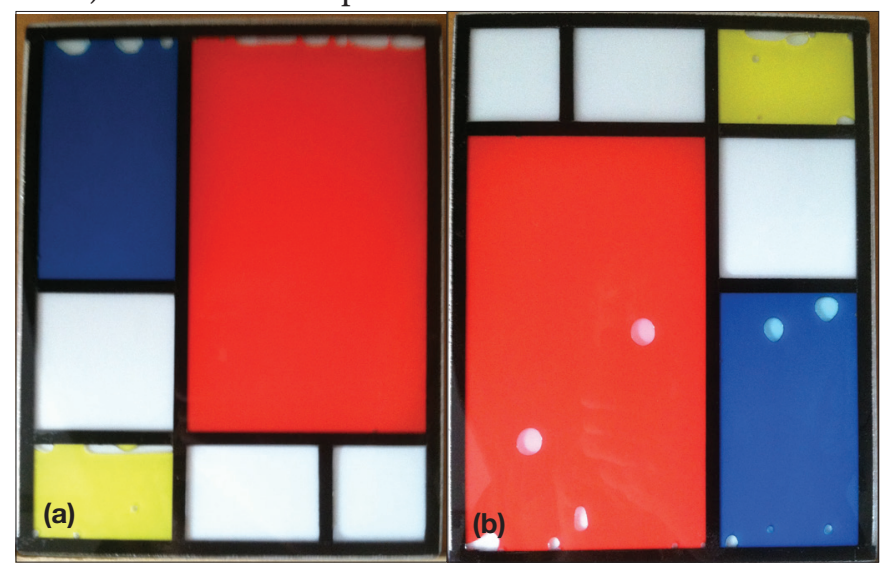

Fig. 1. (a) Dyed glycerin in three separate sections in a thin enclosure, with an overall thickness of $7.9 \mathrm{~mm}$ (5/16 in). (b) After turning the enclosure $180^{\circ}$, air bubbles rise through glycerin. 


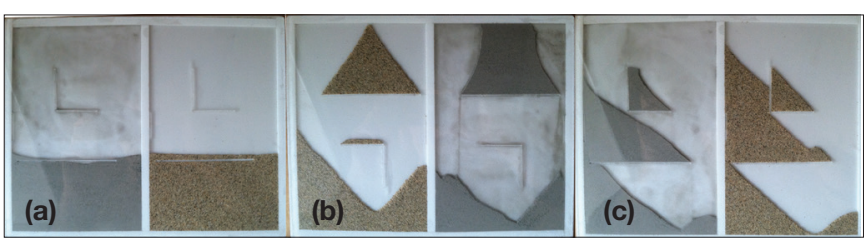

Fig. 2. (a) By rocking the enclosure side to side, sand and CMS (ceramic microspheres) are brought to the silos, under the long partitions. (b) Angle of repose is clearly seen in sand, and clustering is evident in CMS after the enclosure was turned $180^{\circ}$. (c) After more turns, again, uniform angle of repose in sand and variation in CMS.

fabrication tips will be provided upon request.

It is easy to use the enclosure for demonstration. Turn the enclosure upside down vertically, and observe how air bubbles flow to the top, as shown in Fig. 1(b). After several turnings, bubbles are divided into smaller bubbles that result in exhibiting some subtle bubble dynamics, for example tandem-bubble merging, and more visual engagement.

\section{Granular material flow}

Granular materials abound in our world, from sugar on the breakfast table to cement and powder in construction and pharmaceutical industries. They have complex behavior and under certain conditions qualitatively exhibit fluid-like behavior. Understanding physics of granular flow is therefore important because of the diversity of applications in which such materials are handled and processed. ${ }^{6-8} \mathrm{~A}$ number of common characteristics associated with flow of granular materials are demonstrated with the following two devices described in this section.

\section{Angle of repose ${ }^{9}$ and more}

Angle of repose and three other characteristics are demonstrated with a thin enclosure that partially contains, in two separate sections, sand and ceramic microspheres (CMS are used as a thickening agent in epoxies, for example.) The enclosure is designed to visually compare how relatively coarse and fine granular materials flow, side by side. The average CMS grain size is about $0.2 \mathrm{~mm}$ (0.006 in), which is approximately $1 / 10$ th of sand's average grain size.

The enclosure is shown in Fig. 2 and made through the steps similar to those described above for the first device. In addition, thin rods $2 \mathrm{~mm}$ ( $1 / 16 \mathrm{in})$ in diameter cut to various

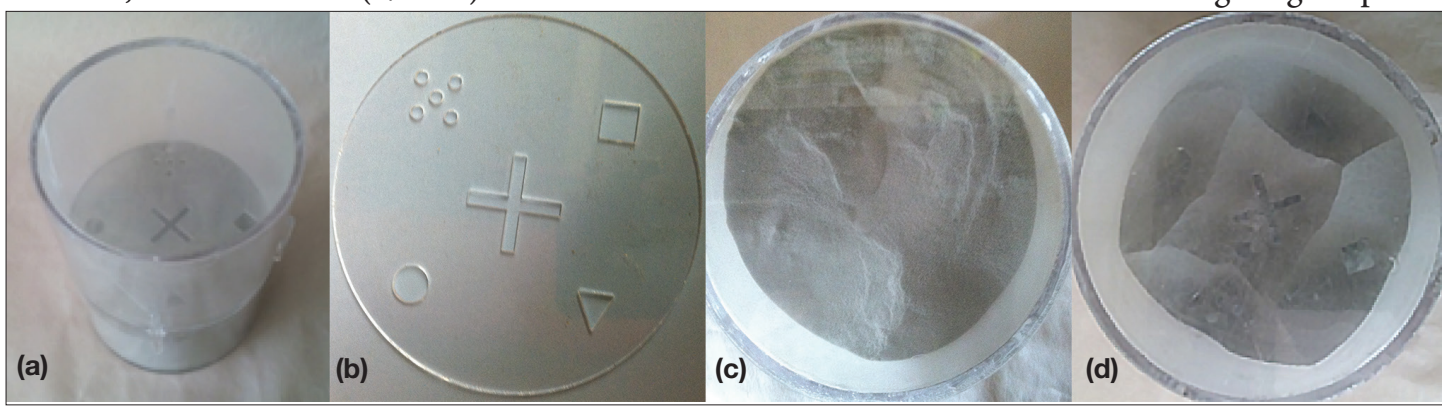

Fig. 3. (a) Overall view of the cylinder showing two chambers with the disk in between them, with all CMS in the lower chamber. (b) Close-up of the separating disk with simple geometrically shaped holes. (c) Upon inverting the cylinder, landslides are seen from top view. (d) The final CMS surface in the top chamber once all holes have been cleared and flow stopped. lengths serve as obstacles or partitions to alter the flow. In each section, one of the partitions runs nearly the entire width with a small gap at left and a larger gap at right [see Fig. 2(a)]. The space between this partition and the lower part of the enclosure can be imagined as a silo in which the granular material is collected, and from which the flow is initiated. The sand and CMS are slowly poured into the enclosure through an improvised trough made of a piece of folded paper that is partially inserted in the opening during the fabrication steps (as described for the first apparatus). About $40 \%$ of the volume in each section is filled with the respective granular material, and the rest is air.

It is easy to use the enclosure to demonstrate angle of repose. Turn the enclosure upside down, or through $90^{\circ}$ steps, in a vertical plane and observe the resulting gravity flow of the sand and CMS. Once the flow stops, angle of repose, i.e., the slope of the pile of granular material, is demonstrated, as seen in Fig. 2(b). Every turn of the enclosure results in a new formation of piles of granular materials, e.g., Fig. 2(c). Notice the slope of the sand pile is uniform and repeatable, while for the CMS the slope is non-uniform and changes with each turn. This erratic clustering of CMS grains near the free edge of the pile is due to cohesion among the CMS grains. Cohesive forces, which become dominant compared to friction and gravity in smaller grain sizes, arise from sources such as van der Waals, electrostatic, or tiny liquid bridges between adjacent grains. Another feature of granular flow is demonstrated with this device. When either material falls through a gap in the aforementioned silo, only a small region near the free surface of the material flows while its bulk remains stationary. Occasionally, air pockets are entrapped in the CMS, again due to cohesion among grains, and this is a demonstration of twophase (gas-solid) in granular flow.

\section{Landslide- and eruption-like flows}

Landslide- and eruption-like flows are demonstrated with a cylinder that contains CMS and air [see Fig. 3(a)]. The cylinder is made of two $10.2-\mathrm{cm}$ (4-in) diameter acrylic tubes (chambers) in tandem. Each chamber is $6.4 \mathrm{~cm}$ (2.5 in) long and capped with a solid clear acrylic disk at its end. A perforated disk with several laser-cut holes is between the two chambers [see Fig. 3(b)]. The CMS was poured into one of the chambers before gluing the perforated disk and the other

chamber. Care was taken to pour the CMS slowly to reduce scattering of its fine dust. Four pieces of 5-mm (3/16-in) rods were glued around the middle of the cylinder to reinforce the assembly.

It is easy to use the cylinder to demonstrate landslide and eruption. Simply turn 
the cylinder upside down and observe the flow of the CMS as it falls through the holes. The flow starts with a series of irregular landslides (similar to avalanches) and eruptions. Each eruption is a venting due to pressure built up in the lower chamber as the CMS flow into that chamber. Notice the order in which the holes are cleared, usually the square-shaped hole first and always the cluster of five small holes last. Sample images are shown in Figs. 3(c)-(d). Occasionally, jamming10 occurs above the cluster of small holes. (Also, I tried sand instead of CMS in the cylinder. The sand flow was steady and quick, i.e., much less cohesion among sand grains, highlighting the importance of grain size in flow behavior.)

\section{Rotational flow instability}

Rotational flow instability, ${ }^{11}$ which is an advanced topic in physics of fluids but easily observable, is demonstrated with a sealed acrylic tube that is vertically held on a turntable. The tube contains dyed rheoscopic fluid (RF), which is water plus pearly crystals (additive) that are sensitive to local shear, thereby enabling flow visualization. The RF is dyed with a few drops of food color.
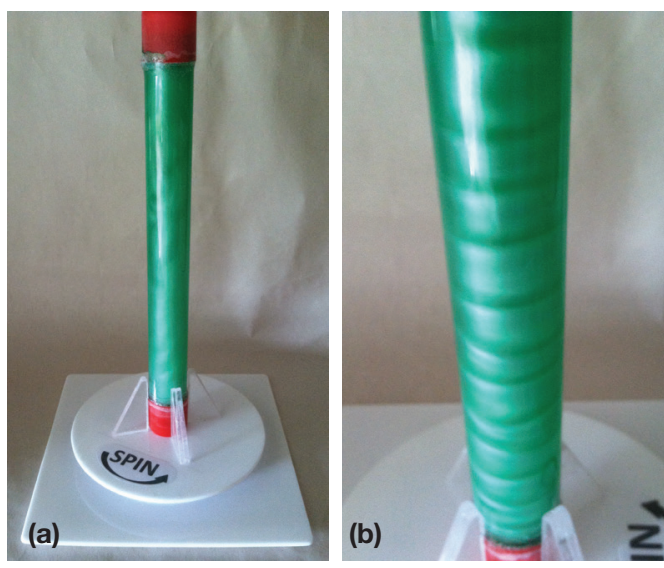

Fig. 4. (a) Sealed $25.4-\mathrm{cm}$ (10-in) long acrylic tube containing dyed rheoscopic fluid on a turntable base. (b) Close-up of vortices as the liquid spins down.

The $2.5-\mathrm{cm}$ (1-in) diameter tube is sealed with acrylic disks at both ends that are then covered with plastic caps. Detailed construction of such a tube (used for a different demonstration) is documented. ${ }^{1} \mathrm{~A} 12.7-\mathrm{cm}$ (5-in) diameter acrylic disk and an acrylic square base $(17.8 \times 17.8 \mathrm{~cm}$ or $7 \times 7$ in) are glued to the top and bottom faces of a $10.2-\mathrm{cm}$ (4-in) diameter plastic turntable. Four small brackets are cut from scrap acrylic sheet and glued to the disk to hold the tube in a vertical orientation.

It is easy to use the tube to demonstrate flow instability due to rotation. Shake the tube to mix the crystals and then place it in its holder. While holding the base with one hand, quickly flick the turntable four or five times to cause about 20 revolutions, and then stop the disk. As the liquid spins down, horizontal rings known as Taylor vortices appear along the tube as a result of secondary flow imposed on the main rotational flow. Sample images appear in Fig. 4. The formation of the vortices is the result of interaction between radial pressure gradient (centrifugal effect) and inertial effect, when the latter overcomes viscous effect.

\section{Wake vortices}

Wake vortices, which form behind an object moving through a fluid, are demonstrated with a thin enclosure. The enclosure contains dyed RF and a large air bubble that serves as the object. Wake vortices are an important consideration in determining drag. To study wake vortices, consult any fluid mechanics textbook that covers external flows. ${ }^{12}$

The enclosure is made of the same materials and via nearly the same fabrication steps described above for the first demonstration, except its frontal dimensions are 30.5 $\mathrm{x} 4.4 \mathrm{~cm}(12 \mathrm{x} 1.75 \mathrm{in})$. Furthermore, a partition made of 2-mm (1/16-in) acrylic rod, with a central gap of 6 $\mathrm{mm}(1 / 4 \mathrm{in})$, is glued in the middle of the enclosure. The purpose of the partition is to break the large air bubble into smaller ones, i.e., to regulate the flow of air bubbles.

It is easy to operate the enclosure for demonstration. Shake the enclosure to mix the crystals in RF. Turn the enclosure upside down. If needed, gently tap the enclosure to break the surface tension of RF to get the air bubbles going at the gap in the partition. Observe the wake vortices as a series of air bubbles rise above the partition. A sample image of the wake

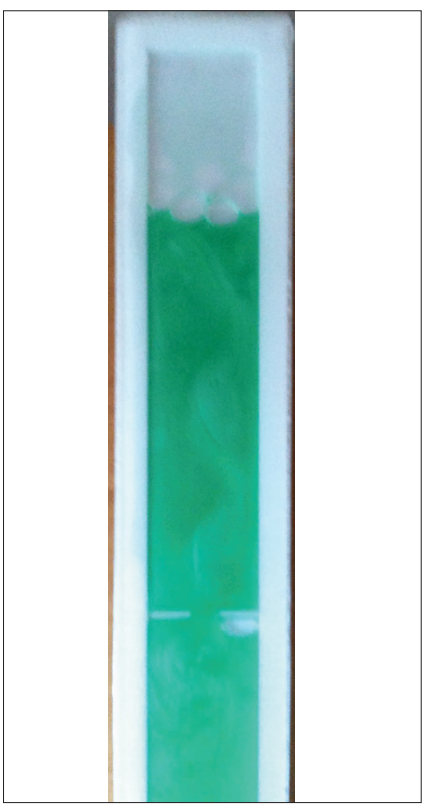

Fig. 5. Traces of wake vortices shown as two consecutive bubbles reach the top. Notice the partition with a central gap near the bottom and the vertically oriented sinusoidal pattern in the fluid above. (The extreme lower part of the enclosure is not shown to save space.) vortices is shown in Fig. 5.

We presented the five devices separately because each can stand on its own without connection to others. However, three of them deal with falling fluids through openings. It is interesting to note that the flow rate of a Newtonian fluid through an opening is a function of hydrostatic pressure, among other factors, but not so for the flow of granular material, as discovered by Janssen in $1895 .^{13}$

\section{Further explorations}

As mentioned before, these devices can be used for various purposes. Here, we provide a list of some potential uses.

1. Lecture demonstration in introductory physics courses, for example, when covering fluid properties such as surface tension, pressure, viscosity, etc.

2. Show-and-tell presentations at outreach activities to demonstrate beauty and complexity of fluid flows to non-experts. 
3. Student projects to build and conduct experiments. Two examples are:

a. Measure the rise of air bubble in glycerin and correlate with bubble size (Device \#1). This can be done, for example, by analyzing video frames.

b. Measure critical rotational speed at the onset of instability (Device \#4). Below critical speed, viscous effect dampens any perturbation and no secondary flow is developed.

4. Collaborative student projects to build similar devices with emphasis on the esthetics. Collaborate with arts majors, for example.

5. Advanced student projects to build large-scale versions of the devices, for example, to donate to local children museums.

\section{Summary}

Due to a simple design, the low-cost devices presented here can be set up instantly and used repeatedly to demonstrate complexity and beauty of several types of fluid and fluid-like flows. They were exhibited at the 2018 AAPT Apparatus Competition ${ }^{14}$ in Washington, D.C.

\section{Acknowledgments}

I would like to express my appreciation to Dr. David Kardelis for his sponsorship, which enabled me to enter the 2018 Apparatus Competition, and also for his willingness to set up and take down the demonstration devices on my behalf. Dr. Jasna Brujic provided a copy of Ref. 10. Dr. Troy Shinbrot, Dr. Christine M. Hrenya, and Dr. Heinrich Jaeger provided insights on cohesive grains. Dr. Christian Ucke provided the correct citation of Ref. 13. An anonymous reviewer made an important correction and provided useful suggestions that improved the quality of the manuscript. The devices were developed as part of a project funded by the Faculty Research Committee of the University of the Pacific.

\section{References}

1. S. Shakerin, "Fluids demonstrations: Trailing vortices, plateau border, angle of repose, and flow instabilities," Phys. Teach. 56, 248-252 (April 2018).

2. For example, view instructional videos on cutting and gluing acrylic at: https://www.tapplastics.com/product_info/videos. Also, type "Acrylic Sheet Fabrication Manual" in your search engine to access a 36-page manual with the same title.

3. To view the Appendix and videos, see TPT Online, http://dx. doi.org/10.1119/1.5135786 under the Supplemental tab.

4. D. Lohse, "Bubble puzzles," Phys. Today 56, 36-41 (Feb. 2003).

5. A. Prosperetti, "Bubbles," Phys. Fluids 16, 1852-1865 (June 2004).

6. H. M. Jaeger, S. R. Nagel, and R. Behringer, "The physics of granular materials," Phys. Today 49, 32-38 (April 1996).

7. J. Kakalios, "Resource Letter GP-1: Granular physics or nonlinear dynamics in a sandbox," Am. J. Phys. 73, 8-22 (Jan. 2005).

8. J. Krim and R. P. Behringer, "Friction, force chains, and falling fruit," Phys. Today 62, 66-67 (Sept. 2009).

9. H. M. B. Al-Hashemi and O. S. B. Al-Amoudi, "A review on the angle of repose of granular materials," Powder Technol. 330, 397-417 (May 2018).

10. J. Brujic, "Jammed particles, from sandy beaches to sunscreens," Phys. Today 63, 64-65 (Nov. 2010).

11. R. J. Donnelly, "Taylor-Couette flow: The early days," Phys. Today 44, 32-39 (Nov. 1991).

12. A. J. Smits, A Physical Introduction to Fluid Mechanics, 2nd ed. (self-published, Princeton, 2017), pp. 181-187. Available free at: http://www.efluids.com/efluids/books/Smits_text_part1.pdf.

13. H. A. Janssen, "Versuche über Getreidedruck in Silozellen," $Z$. Ver. Dtsch. Ing. 39, 1045-1049 (August 1895).

14. Apparatus Competitions are archived at: https://www.aapt.org/ Programs/contests/apparatus_home.cfm.

Said Shakerin has been with the Department of Mechanical Engineering at University of the Pacific since 1986. He enjoys developing sciencebased demonstrations for informal science education. sshakerin@pacific.edu

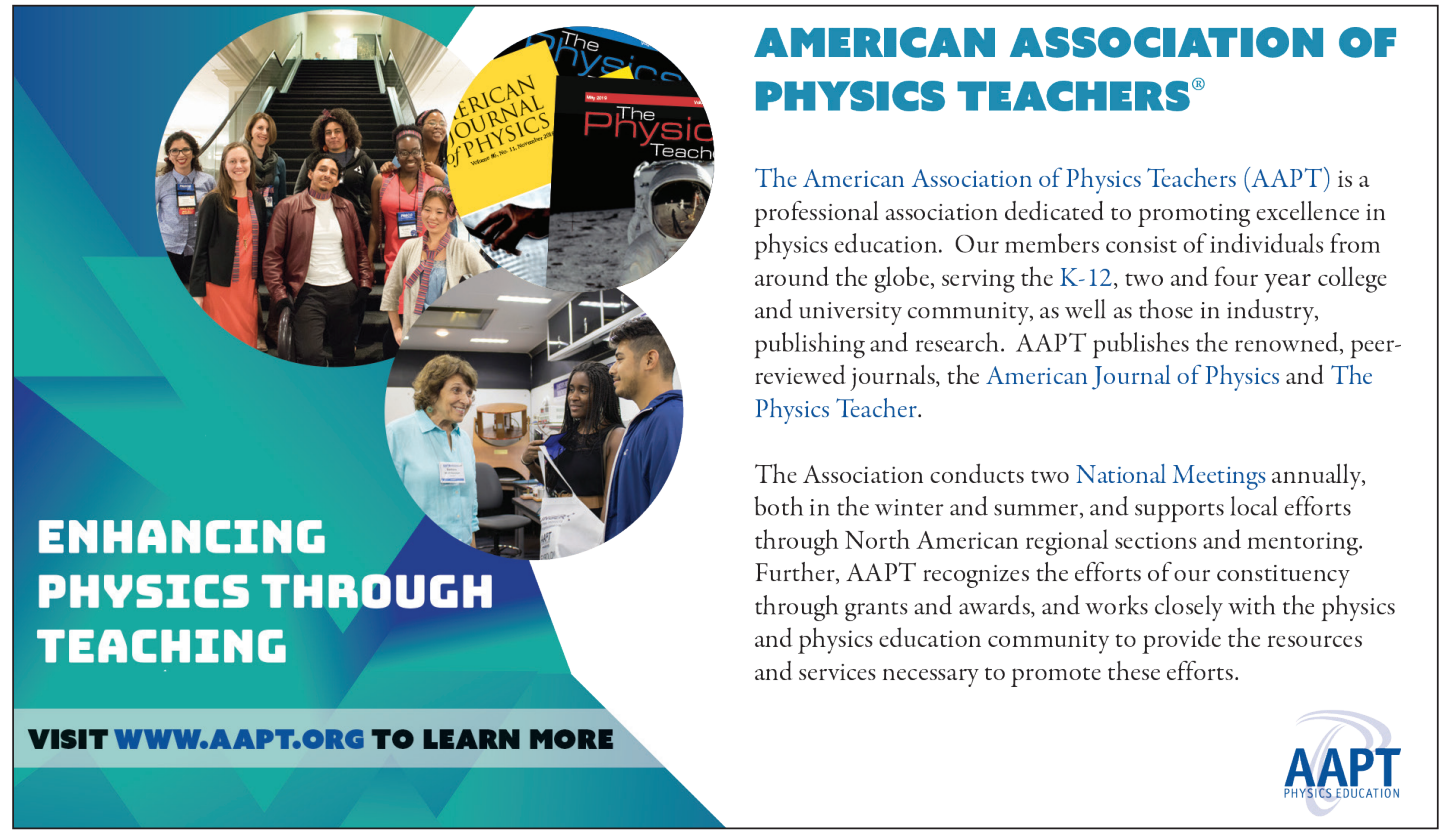

